\title{
Análise das imagens de história da vida em livros didáticos de biologia do ensino médio
}

Steve Allen Davi de Lima steve.allen@aluno.uece.br http://orcid.org/0000-0002-6136-2932 Universidade Estadual do Ceará (UECE), Itapipoca, Ceará, Brasil

Mário Cézar Amorim de Oliveira

mario.amorim@uece.br Universidade Estadual do Ceará (UECE), Itapipoca, Ceará, Brasil

Marcelo D'Aquino Rosa marcelo.rosa@ifsc.edu.br $\frac{\text { http://orcid.org/0000-0002-0111-8540 }}{\text { Instituto Federal de Ciência e Tecnologia }}$ de Santa Catarina (IFSC), Florianópolis, Santa Catarina, Brasil

\section{RESUMO}

O curso de Licenciatura em Ciências Biológicas deve possibilitar aos licenciandos a compreensão de como a vida se organizou durante o tempo, implicando na compreensão dos mecanismos evolutivos como eixo integrador da formação inicial docente. Diante disso, a história mostra que desde que o homem começou a se questionar acerca da origem dos primeiros seres vivos, ideias de cunho mitológico, filosófico, religioso e científico foram esboçadas e ganharam enorme espaço nas discussões acerca da História da Vida (HV). Essas discussões estão presentes nas aulas de Biologia do Ensino Médio, muitas vezes reverberando em explicações miscigenadas que dificultam a apropriação do conhecimento biológico. Em nossa investigação, consideramos a HV como um tópico de ensino da Evolução Biológica (EB), por dizer respeito aos processos macroevolutivos responsáveis pelo surgimento dos grandes grupos de seres vivos. Diante do exposto, o objetivo desta pesquisa é verificar o papel didático das imagens relacionadas à HV presentes nos LD de Biologia do Ensino Médio aprovados na edição de 2018 do Programa Nacional do Livro Didático (PNLD2018). Nessa perspectiva optamos pelo uso de um instrumento analítico, construído a partir de referenciais de análise semiótica, para compreender os aspectos imagéticos acerca do assunto HV no material investigado. Dessa forma, verificamos que a maioria das imagens analisadas pode ser classificada como inoperante, ou seja, sem nenhuma funcionalidade além da pura observação. Nesse aspecto, pesa o fato de que as imagens têm sido cada vez mais utilizadas nos LD a fim de melhorar a compreensão dos conteúdos conceituais da Biologia. Assim, para que os conteúdos imagéticos consigam atender às demandas esperadas por eles no processo de ensino-aprendizagem, novas investigações neste âmbito precisam ser realizadas.

PALAVRAS-CHAVE: Evolução Biológica. Macroevolução. Análise Imagética. PNLD-2018. 


\section{INTRODUÇÃO}

O termo Biologia, a ciência que estuda os seres vivos, apareceu pela primeira vez, e de forma independente, nos trabalhos de dois naturalistas: na França, com Jean-Baptiste de Lamarck (1744-1829), e no mesmo período, na Alemanha, através de Gottfried R. Treviranus (1776-1837). Embora a ciência tenha sido nomeada apenas no início do século XIX, o estudo dos seres vivos remonta a séculos anteriores, sendo um dos alicerces para o estabelecimento do conhecimento da civilização ocidental (ARAÚJO; MENEZES; COSTA, 2012).

Desde que o homem começou a se questionar acerca da origem dos primeiros seres vivos, uma diversidade de explicações foi se construindo a partir de diferentes pressupostos, consolidando concepções de diferentes naturezas que muitas vezes eram defendidas calorosamente pelos mais variados setores da sociedade. Ao longo do tempo, ideias de cunho mitológico, filosófico, religioso e científico foram sendo construídas em todo o globo (NICOLINI et al. 2010) e demandam espaço nos debates acerca da História da Vida (HV), sobretudo nas aulas de Biologia. Essas explicações muitas vezes implicam em construções miscigenadas que podem dificultar a apropriação do conhecimento biológico acerca do fenômeno vida, seu surgimento e evolução. Oliveira (2009) aponta em sua investigação que, a depender dos compromissos com suas crenças religiosas e da implicação das explicações científicas para a diversidade biológica pelo processo evolutivo, os estudantes estariam mais propensos a aceitar ou rejeitar as explicações biológicas, impactando na sua abertura ou não para o aprendizado.

Nesse sentido, é importante se discutir a temática HV, já que esta é caracterizada como o estudo para explicar os processos pelos quais os organismos evoluíram (BENTON, 2012) e que se apresenta muitas vezes como um assunto passível de controvérsias (OLIVEIRA, 2011), que podem tornar ainda mais complexo o processo de ensino-aprendizagem de Biologia na escola. Assim, nessa investigação, a HV é tratada como um tópico de ensino da Evolução Biológica (EB). Além disso, é necessário enfatizar os limites temáticos e conceituais de interesse nessa pesquisa, pois quando se procura compreender, em um contexto mais abrangente, a temática HV, transita-se por assuntos como a Origem da Vida (OV) e os mecanismos e padrões que explicam a evolução nas escalas micro e macroevolutiva. Optou-se, desse modo, por investigar o assunto relacionado à sua abordagem nos livros didáticos (LD) de Biologia do Ensino Médio, delimitando à temática dos processos ao nível macroevolutivo (evolução dos grandes grupos de seres vivos) da vida e suas concepções.

Diante do exposto, com esse texto, que compõe uma investigação mais ampla, procuramos responder a seguinte questão de pesquisa: Quais características possuem as imagens relacionadas ao tópico História da Vida presentes nos livros didáticos do componente curricular de Biologia do Ensino Médio? Desse modo, delimitou-se que o objetivo desse trabalho é verificar o papel didático das imagens relacionadas à HV presentes nos LD de Biologia do Ensino Médio aprovados na edição de 2018 do Programa Nacional do Livro Didático (PNLD-2018). Desse modo, nas seções seguintes abordaremos brevemente a história do LD de Biologia e da HV no ensino de EB, como também o papel das imagens nos LD, de forma a fundamentar teoricamente esse estudo. 


\section{A HISTÓRIA DA VIDA, O LIVRO DIDÁTICO DE BIOLOGIA E SEU ENSINO}

O LD possui um importante papel no ensino dos conteúdos escolares em sala de aula (ROSA; ARTUSO, 2019), especialmente no que se relaciona ao entendimento de conhecimentos científicos, dado sua complexidade e a necessidade de um direcionamento mais específico por parte do educador. Assim, "muito embora não seja o único material de que professores e alunos vão valer-se no processo de ensino e aprendizagem, ele pode ser decisivo para a qualidade do aprendizado resultante das atividades escolares" (LAJOLO, 1996, p.4).

O LD assume cada vez mais um papel central na prática de ensinoaprendizagem de Biologia, em virtude tanto de sua distribuição gratuita para as escolas públicas em todo o território nacional, sendo muitas vezes o único material disponível para estudantes fora dos grandes centros, como também em função da prática de muitos professores que, talvez por apresentarem limitada preparação nos processos de seleção dos LD e de seus conteúdos, tarefa que muito exige de uma classe de profissionais que pouco têm recebido em termos de saberes, competências, habilidades, para tal fim (NUÑES, et al. 2001), ficam limitados a incorporar acriticamente os conhecimentos veiculados por esse recurso. Por lacunas formativas, docentes adotam e utilizam este recurso confiando diretamente no conteúdo nele impresso, sem atentar, por exemplo, que este material pode conter informações distorcidas e equivocadas, mesmo após o processo criterioso de avaliação realizado no contexto do Programa Nacional do Livro Didático (PNLD).

Nessa perspectiva, Nuñes et al. (2001) entendem que o LD não pode continuar como única fonte a ser utilizada pelo educador com fins memorísticos ou repetitivos para os alunos. O professor deve desenvolver saberes e competências para superar tais limitações, uma vez que, o caráter genérico dos LD, muitas vezes não contextualiza problemáticas locais. Diante disso, é tarefa dos professores complementar e dar maior significado aos LD recomendados pelo MEC (NUÑES, et al. 2001), principalmente quando se trata da abordagem de conhecimentos científicos cuja dinamicidade de produção exige constante atualização, tais como os relacionados à Biologia Evolutiva.

Nesse contexto, um tópico imprescindível da Biologia Evolutiva é a macroevolução, que pode ser entendida como a evolução em larga escala, sendo estudada principalmente a partir do registro fóssil. Refere-se à evolução acima do nível de espécie, englobando as maiores tendências e transformações na evolução. A macroevolução contrasta assim com a microevolução, que consiste no conjunto de mecanismos que atuam em curtos períodos de tempo, como de uma vida humana ou menos. Eventos de processos macroevolutivos são muito mais propensos a levar milhões de anos, referindo-se a eventos como a origem de grandes grupos de seres vivos ou os de extinção em massa, por exemplo (DIAS, 2018).

Antes de se apresentar uma sumarização dos recentes avanços no conhecimento acerca da macroevolução, assunto inserido no eixo temático EB, nos LD de Biologia, devemos incialmente tomar como parâmetro de análise a ideia de que a evolução não seria uma parte da Biologia, senão que uma ampla orientação para a produção de explicações nas mais diversas áreas desta ciência, e que o enfoque a respeito da macroevolução deve ser discutido. 
A esse respeito, é necessário compreender que além da problemática que circunda a temática $E B$, esta muitas vezes não compreendida corretamente e não reconhecida como eixo unificador das Ciências Biológicas, apresenta ainda distanciamentos conceituais e dificuldades dentro do próprio conteúdo, como por exemplo, os processos macroevolutivos. Nesse sentido, optamos por iniciar apresentando os principais obstáculos à abordagem específica desse conteúdo, para em seguida apresentar os mais recentes conhecimentos científicos acerca do assunto.

Inicialmente, uma das principais dificuldades relacionadas ao assunto HV, entendida aqui como macroevolução, é observada quando se procura abordar os processos evolutivos. Nestes, geralmente apenas a seleção natural e mutação são destacados em sala de aula (BIZZO; EL-HANI, 2009). Especificamente a esse respeito, Salgado-Labouriau (2014) alerta que boa parte da literatura explica a evolução dos seres vivos exclusivamente pelo mecanismo de seleção natural de Charles Darwin.

Além disso, o assunto macroevolução muitas vezes é negligenciado, como afirmam Bizzo e El-Hani (2009). Os exemplos que geralmente compõem o ensino tradicional de EB apoiam essa constatação: melanismo industrial em mariposas, alongamento do pescoço das girafas e aumento de resistência bacteriana a antibióticos. Esses são todos exemplos de microevolução (COSTA, 2017) e provavelmente essa incidência pode estar relacionada com o enfoque dominante ou exclusivo sobre o mecanismo de seleção e mutação, como anteriormente argumentado.

Já quando se trata da perspectiva macroevolutiva, as questões são direcionadas, por exemplo, para as razões pelas quais certos grupos se diversificaram e outros se extinguiram, as razões de certas linhagens de organismos sofrerem mudanças profundas na sua forma em milhares de anos e outras praticamente nada mudarem ao longo desse tempo. Em outras palavras, as questões macroevolutivas sempre tratam de entender fenômenos que envolvem espécies ou níveis taxonômicos acima das espécies (COSTA, 2017).

Nesse aspecto, quando buscamos descrever a HV na Terra, podemos evidenciar o acontecimento de vários eventos macroevolutivos surpreendentes, como a Explosão do Cambriano, a rápida diversificação das plantas terrestres durante o devoniano, a fauna de Ediacara ao final do Neoproterozóico, a evolução dos cetáceos, a expansão do homem durante o pleistoceno, e os conhecidos eventos de extinção em massa (DAWKINS, 2009).

A ideia de atingir um melhor entendimento dos processos envolvidos na HV, não se resume a exclusão da escala microevolutiva em favorecimento da escala macroevolutiva, e sim a correta interpretação desta última, sobretudo, a sua presença nos LD de Biologia, uma vez que a HV se constitui a partir do somatório destas duas escalas, a micro e a macroevolutiva. Somado a isso, nosso entendimento acerca da importância dos aspectos macroevolutivos para a EB como um todo é apoiado nas conclusões de Costa (2017, p. 70), para quem 
coerentemente muitos eventos evolutivos importantes para a biologia, especialmente os de natureza macroevolutiva - como os eventos de diversificação, as tendências evolutivas e as extinções em massa. (COSTA, 2017, p. 70)

Os fósseis são evidências importantes que oferecem elos para a (re)construção da história evolutiva dos grandes grupos de seres vivos. É justamente sobre a evidência fóssil que um marco importante, ocorrido ainda no século XIX, fez com que as informações das investigações biológicas, que até então acumulavam-se de forma desarticulada, ganhassem um novo sentido e uma coerência a partir da reinterpretação das relações existentes entre os organismos vivos. É no ano de 1859, que Charles Darwin (1809-1882) publica seu livro "Da Origem das Espécies por meio da seleção natural ou a Preservação de raças favorecidas na luta pela vida", cujo título foi abreviado na sexta edição (1872) para "A Origem das Espécies", como é conhecido hoje, obtendo êxito em agrupar e organizar uma grande quantidade de evidências que explicassem a evolução (LICATTI, 2005).

Além de Darwin, a contribuição de outros autores, como Benton (2012) e Dawkins (2009), referências no assunto HV, ajudam a traçar linhas de raciocínio no que se refere à abordagem do assunto macroevolução nos LD de Biologia. Seus escritos apresentam alguns conceitos importantes, como os já mencionados por Costa (2017), que enfatizam a contextualização e a forma como o conteúdo pode ser organizado.

Voltando-se a atenção para os documentos oficiais orientadores do currículo no país, a Base Nacional Comum Curricular (BNCC) para o componente curricular Biologia, que integra a área de Ciências da Natureza e suas Tecnologias, embora passível de críticas de várias ordens, apresenta o eixo temático EB, direcionado para abordagem da escala macroevolutiva.

A Base Nacional Comum Curricular (BNCC) "é um documento de caráter normativo que define o conjunto orgânico e progressivo de aprendizagens essenciais que todos os alunos devem desenvolver ao longo das etapas e modalidades da Educação Básica." (BRASIL, 2017, p. 8). De acordo com o texto introdutório da BNCC, o ensino deve ser pautado em competências e habilidades (BRASIL, 2017).

Nesse cenário, a BNCC da área de Ciências da Natureza e suas Tecnologias, integrada por Biologia, Física e Química, propõe que sejam trabalhadas três temáticas principais: Matéria e Energia; Vida e Evolução; e Terra e Universo. Na orientação para o Ensino Médio, o documento sugere que essas duas últimas temáticas (Vida e Evolução; Terra e Universo) podem ser unificadas de forma a possibilitar aos estudantes uma compreensão mais ampla dos processos relacionados a esses assuntos centrais (BRASIL, 2017). Segundo o documento, "isso significa considerar a complexidade relativa à origem, evolução e manutenção da vida [...]" (BRASIL, 2017, p. 538).

Dentre as competências exigidas para essa área, o documento sugere que alguns conhecimentos podem ser mobilizados e relacionados a: EB; registro fóssil; e origem e extinção das espécies (BRASIL, 2017). Além disso, atrelada a essa competência, a habilidade exigida é de "analisar e utilizar modelos científicos, 
propostos em diferentes épocas e culturas para avaliar distintas explicações sobre o surgimento e a evolução da Vida, da Terra e do Universo" (BRASIL, 2017, p. 543).

Verifica-se assim, que a linha orientadora defendida nessa investigação está adequada às proposições formativas possibilitadas pela BNCC, no sentido de contemplar os conhecimentos necessários ao entendimento do eixo temático $\mathrm{EB}$, sobretudo na escala macroevolutiva. Entretanto, cabe salientar que a nova BNCC se encontra em fase de implementação na Educação Básica e, apesar de apresentar boas recomendações no trabalho com a temática $E B$, ainda não é possível verificar efeitos práticos de suas propostas na rotina escolar e, mais especificamente, no ensino de Biologia, até o presente momento, sem levar em consideração os outros fatores que influenciam na construção do currículo escolar.

Para superar as problemáticas relacionadas ao ensino de macroevolução, Costa (2017) argumenta que é importante a abordagem de noções objetivas acerca da operação dos processos microevolutivos e dos efeitos dessa escala sobre os padrões macroevolutivos, mas que também é necessário que o conhecimento sobre processos exclusivamente macroevolutivos estejam presentes. Essa perspectiva é fundamental para que haja um completo entendimento de que as duas escalas (micro e macroevolutivas) estão conectadas de modo não linear e que ambas são relevantes na compreensão adequada da EB.

Diante do exposto anteriormente sobre a organização do assunto macroevolução nos LD de Biologia, a síntese das ideias apresentadas sugere a abordagem sobre eventos macroevolutivos, com a perspectiva da noção de tempo profundo, evidenciando a importância dos fósseis nos processos de datação, classificação geológica, e explicação plausível para os eventos de extinção em massa; a compreensão do pensamento filogenético, que inclui a noção de ancestral comum recente e filogenia; e por fim, a relação entre micro e macroevolução, fazendo a devida distinção entre estas duas escalas.

Paralelamente, outros aspectos são importantes de serem atentados no que se refere a abordagem da HV, tais como o favorecimento da contextualização e a integração das diversas áreas das Ciências Biológicas com outras áreas de pesquisa como a Paleontologia e a Geologia, além disso, a compreensão de que a EB, sobretudo, os aspectos macroevolutivos explorados nesse documento monográfico, perpassa por uma abordagem histórica. Entretanto, em função dos limites de espaço desse texto, tais aspectos não serão contemplados em nossa investigação, e discutiremos brevemente a seguir os papéis que podem ser desempenhados pelas imagens no contexto dos LD de Biologia para o Ensino Médio (EM).

\section{PAPÉIS DAS IMAGENS NOS LIVROS DIDÁTICOS DE BIOLOGIA}

Segundo Santaella (2002), as imagens, como representações visuais, são objetos materiais que representam nosso ambiente visual, podendo ser gravuras, desenhos, pinturas, fotografias e outros artefatos pictóricos. Além disso, a partir da semiótica, o conceito de imagem e de seu papel na produção textual podem ser interpretados de diferentes formas. Barros e Carneiro (2005), por exemplo, endossam essa polissemia do termo, apontando a necessidade de uma melhor compreensão do conceito. 
Nesse estudo, a imagem será considerada uma representação visual, dotada de algum grau de iconicidade, entendida aqui como uma representação, de um ser, fenômeno ou objeto, sendo estes dependentes da percepção de um determinado sujeito, que uma vez ou outra necessitará de algum tipo de complementação, legenda ou texto e que, não compreendida durante sua leitura pelo aluno, possivelmente influencie negativamente nos conteúdos ensinados pelo docente (JOTTA, 2005) ou veiculados por materiais didáticos, tais como o LD.

Coutinho e colaboradores (2010) refletem sobre a importância de se compreender como se dá o uso de imagens nos LD de Biologia e com isso sugerir maneiras de se incorporar imagens e texto verbal nesses recursos didáticos. Dessa forma, uma vez conhecidos os obstáculos a uma aprendizagem eficiente promovidos pela diagramação e planejamento inadequados do LD, o docente pode desenvolver e, especialmente, utilizar estratégias que minimizem os problemas encontrados relacionados ao uso dessas ilustrações.

Com essa finalidade, para realizar uma análise do papel das imagens de anatomia e fisiologia humanas, Ferreira (2014; FERREIRA; OLIVEIRA, 2016) organizou critérios baseados na semiótica para compor uma ficha analítica que utilizaremos, com adaptações, nessa investigação. O primeiro grupo de categorias diz respeito à "Análise em função do grau de iconicidade" das imagens, que pode ser compreendida a partir do Quadro 1, a seguir.

Quadro 1 - Categorias de análise em função do grau de iconicidade

\begin{tabular}{|c|c|}
\hline Categoria & Definição \\
\hline Fotografia & $\begin{array}{c}\text { Quando ocorre a interpretação do espaço e da realidade } \\
\text { através da imagem. }\end{array}$ \\
\hline Desenho figurativo & $\begin{array}{l}\text { Valoriza a representação orgânica, mostrando objetos } \\
\text { mediante a imitação. }\end{array}$ \\
\hline $\begin{array}{l}\text { Desenho figurativo com } \\
\text { signos }\end{array}$ & $\begin{array}{c}\text { Representa ações ou magnitudes inobserváveis em um } \\
\text { espaço de representação heterogêneo. }\end{array}$ \\
\hline $\begin{array}{l}\text { Desenho figurativo com } \\
\text { signos normalizados }\end{array}$ & $\begin{array}{c}\text { A ilustração representa figurativamente uma situação e } \\
\text { paralelamente se representam alguns aspectos } \\
\text { relevantes mediante signos normalizados. }\end{array}$ \\
\hline Desenho esquemático & $\begin{array}{l}\text { A ilustração valoriza os detalhes na representação das } \\
\text { relações. }\end{array}$ \\
\hline $\begin{array}{l}\text { Desenho esquemático } \\
\text { com signos }\end{array}$ & $\begin{array}{l}\text { A ilustração representa ações ou magnitude } \\
\text { inobserváveis. Gráficos e tabelas podem ser } \\
\text { considerados como integrantes desta categoria. }\end{array}$ \\
\hline $\begin{array}{l}\text { Desenho esquemático } \\
\text { com signos normalizados }\end{array}$ & $\begin{array}{l}\text { A ilustração constitui um espaço de representação } \\
\text { homogêneo e simbólico que possui regras sintáticas } \\
\text { específicas. }\end{array}$ \\
\hline
\end{tabular}

Fonte: Ferreira (2014, p. 27).

Quanto à funcionalidade, que, segundo Ferreira e Oliveira (2016) se refere à utilização das representações gráficas como forma de expressar ideias, as imagens nos LD podem ser organizadas nas categorias cuja descrição pode-se ver no Quadro 2. É importante que as imagens vinculadas a quaisquer assuntos nos LD tenham uma função didática específica, e não estejam presentes somente para fins estéticos, como uma forma de chamar e manter a atenção do estudante. Compreendemos que se imagens serão veiculadas nos LD de Biologia, que sejam utilizadas como um recurso explicativo, tendo funções para além da estética. 
Quadro 2 - Categorias de análise em função da funcionalidade

\begin{tabular}{|c|c|}
\hline Função & Definição \\
\hline Inoperantes & Não apresenta nenhum elemento utilizável, só cabe \\
observá-la.
\end{tabular}

Fonte: Ferreira (2014, p. 28).

Segundo Gibin, Kiill e Ferreira (2009), a informação presente nas imagens se apresenta descontínua e somente quando incluídas no texto podem lhe proporcionar um significado. Nesse sentido, essas representações podem estar isoladas do texto, em interação ou diretamente interligadas ao texto (FERREIRA, 2014; FERREIRA; OLIVEIRA, 2016), que são parâmetros utilizados no conjunto de categorias descritas no Quadro 3, correspondente à "Relação entre as imagens e o texto principal".

Quadro 3 - Categorias de análise em função da relação com o texto principal

\begin{tabular}{|c|c|}
\hline Categoria & Definição \\
\hline Conotativa & $\begin{array}{c}\text { O texto descreve os conteúdos sem mencionar } \\
\text { sua correspondência com os elementos inclusos } \\
\text { na ilustração. Supõe-se que estas sejam obvias e } \\
\text { que o próprio leitor possa fazê-las. }\end{array}$ \\
\hline Denotativa & $\begin{array}{c}\text { O texto estabelece a correspondência entre os ele } \\
\text { mentos da ilustração e os conteúdos } \\
\text { apresentados. }\end{array}$ \\
\hline Sinóptica & $\begin{array}{c}\text { De caráter denotativo, estabelece as condições } \\
\text { nas quais as relações entre os elementos inclusos } \\
\text { na ilustração representem as relações entre os } \\
\text { conteúdos, de modo que a imagem e o texto } \\
\text { formam uma unidade indivisível. }\end{array}$ \\
\hline
\end{tabular}

Fonte: Ferreira (2014, p. 28).

Em algumas imagens se verifica a inclusão de textos que contribuem no processo de interpretação da representação, denominados de etiquetas verbais (FERREIRA; OLIVEIRA, 2016). A presença das etiquetas verbais e sua função quando presente compõem o conjunto de categorias denominadas de "Análise em função das etiquetas verbais", descritas no Quadro 4.

Quadro 4 - Categorias de análise em função das etiquetas verbais

\begin{tabular}{|c|c|}
\hline Função & Definição \\
\hline Sem etiqueta & A ilustração não contém texto algum. \\
\hline Nominativa & $\begin{array}{c}\text { Letras ou palavras que identificam } \\
\text { alguns elementos da ilustração. }\end{array}$ \\
\hline Relacionável & $\begin{array}{c}\text { Textos que, para além de identificar, } \\
\text { descrevem as relações entre os } \\
\text { elementos da ilustração. }\end{array}$ \\
\hline
\end{tabular}

Fonte: Ferreira (2014, p. 29).

Outros parâmetros de análise semiótica também podem ser incorporados em uma ferramenta para análise de imagens em LD. Ferreira (2014) utilizou, por 
exemplo, o papel das imagens na composição da sequência didática estabelecida na unidade (seção) do LD analisada, podendo as imagens terem papel de evocação, definição, aplicação, descrição, interpretação ou problematização. Entretanto, no contexto dessa investigação, somente quatro categorias organizadas por Ferreira (2014) e em Ferreira e Oliveira (2016) foram utilizadas, o que detalharemos na seção a seguir.

\section{PROCEDIMENTOS METODOLÓGICOS DA INVESTIGAÇÃO}

Nosso estudo caracteriza-se por uma abordagem qualitativa de natureza exploratória pois, segundo Gil (2002, p. 90) as pesquisas qualitativas são como “[...] um vaivém entre observação, reflexão e interpretação à medida que a análise progride" e, mesmo fazendo uso de dados numéricos e, em alguma medida, quantitativos, requerem uma maior aproximação do pesquisador com os objetos de estudo, procurando construir resultados comprometidos com os dados estudados, o que contribui para a maior validade da investigação. A investigação é exploratória por buscarmos uma "[...]maior familiaridade com o problema, com vistas a torna-lo mais explícito ou a constituir hipóteses" (GIL, 2002, p. 41).

Para a análise dos dados imagéticos coletados nas coleções de LD de Biologia, utilizamos elementos de análise semiótica organizados em um dispositivo/instrumento de pesquisa. Os dados imagéticos, entendidos aqui como as ilustrações relacionadas ao conteúdo do LD, foram analisados através do uso de uma "ficha analítica", elaborada por Ferreira (2014; FERREIRA; OLIVEIRA, 2016) e modificada para atender às especificidades dessa investigação. Originalmente composta por cinco categorias, nessa investigação optamos por excluir a quinta categoria, a "Análise em função das sequências didáticas", por entendermos que se refere à organização estrutural das imagens em relação ao texto, aspecto não contemplado em nossa investigação com as imagens.

Nesse sentido, a ficha analítica (Apêndice A) utilizada como instrumento em nossa investigação, fundamentada em autores de análises semióticas, segundo Ferreira (2014) e Ferreira e Oliveira (2016), foi elaborada a partir de quatro grupos de categorias, a saber: Análise em função 1. "do grau de iconicidade", 2. "da funcionalidade", 3. "da relação com o texto principal", e 4. "das etiquetas verbais".

A etapa seguinte consistiu na delimitação dos conteúdos que abordam a HV, compreendida como a evolução dos grandes grupos de seres vivos ou macroevolução, presente nas dez (10) coleções de LD de Biologia do Ensino Médio aprovadas na edição de 2018 do Programa Nacional do Livro Didático (PNLD-2018). No quadro 5 a seguir, apresentamos a lista dos LD analisados nessa investigação, indicando a codificação utilizada para cada LD, o título da referida coleção, seus autores, e a editora responsável pela publicação. Essa codificação foi criada a partir da ordem de apresentação das obras no Guia do Livro Didático do PNLD-2018 (BRASIL, 2017).

Todas as coleções (cada qual composta de 3 volumes, um para cada ano letivo do Ensino Médio) foram investigadas para identificar a presença de conteúdos relacionados à HV, mesmo que a experiência docente dos autores dessa investigação apontasse fortemente para a presença do tema HV somente nos LD voltados para o 3o ano do Ensino Médio (EM). 
Quadro 5 - LD utilizados na investigação

\begin{tabular}{|c|c|c|c|c|}
\hline Código & Volume & Título & Autor/A (Es/As) & Editora \\
\hline A1 & 1읏 Ano & \multirow{3}{*}{ BIOLOGIA HOJE } & \multirow{3}{*}{$\begin{array}{c}\text { Fernando Gewandsznajder, } \\
\text { Helena Pacca e Sérgio } \\
\text { Linhares }\end{array}$} & \multirow{3}{*}{ Ática } \\
\hline $\mathrm{A} 2$ & 2o Ano & & & \\
\hline A3 & 3o Ano & & & \\
\hline B1 & 1읏 Ano & \multirow{3}{*}{$\begin{array}{l}\text { INTEGRALIS- } \\
\text { BIOLOGIA: } \\
\text { NOVAS BASES }\end{array}$} & \multirow{3}{*}{ Nélio Marco Vicenzo Bizzo } & \multirow{3}{*}{ IBEP } \\
\hline B2 & 2ㅇ Ano & & & \\
\hline B3 & 3o Ano & & & \\
\hline C1 & 1ㅇ Ano & \multirow{3}{*}{$\begin{array}{c}\text { SER } \\
\text { PROTAGONISTA } \\
\text { - BIOLOGIA }\end{array}$} & \multirow{3}{*}{$\begin{array}{c}\text { André Catani, Antonio C. } \\
\text { Bandouk, Elisa Garcia } \\
\text { Carvalho, Fernando S. dos } \\
\text { Santos, João Batista Aguilar, } \\
\text { Juliano Viñas Salles, Lia M. } \\
\text { Bezerra, Maria Martha de } \\
\text { Oliveira, Sílvia Helena de A. } \\
\text { Campos, Tatiana Nahas e } \\
\text { Virginia Chacon }\end{array}$} & \multirow{3}{*}{ SM } \\
\hline $\mathrm{C} 2$ & 2ㅇ Ano & & & \\
\hline C3 & 3ㅇ Ano & & & \\
\hline D1 & 10 Ano & \multirow{3}{*}{ BIOLOGIA } & \multirow{3}{*}{$\begin{array}{c}\text { César da Silva Júnior, Sezar } \\
\text { Sasson e Nelson Caldine } \\
\text { Júnior }\end{array}$} & \multirow{3}{*}{ Saraiva } \\
\hline D2 & 2ㅇ Ano & & & \\
\hline D3 & 3ㅇ Ano & & & \\
\hline E1 & 1ㅇAno & \multirow{3}{*}{$\mathrm{BIO}$} & \multirow{3}{*}{$\begin{array}{c}\text { Sônia Godoy Bueno Carvalho } \\
\text { Lopes e Sérgio Rosso }\end{array}$} & \multirow{3}{*}{ Saraiva } \\
\hline E2 & 2Ano & & & \\
\hline E3 & 3ㅇ Ano & & & \\
\hline $\mathrm{F} 1$ & 1응 Ano & \multirow{3}{*}{$\begin{array}{l}\text { \#CONTATO } \\
\text { BIOLOGIA }\end{array}$} & \multirow{3}{*}{$\begin{array}{l}\text { Leandro Godoy e } \\
\text { Marcela Ogo }\end{array}$} & \multirow{3}{*}{ Quinteto } \\
\hline $\mathrm{F} 2$ & 2ㅇ Ano & & & \\
\hline F3 & 3ㅇ Ano & & & \\
\hline G1 & 10 Ano & \multirow{3}{*}{$\begin{array}{l}\text { BIOLOGIA - } \\
\text { UNIDADE E } \\
\text { DIVERSIDADE }\end{array}$} & \multirow{3}{*}{ José Arnaldo Favaretto } & \multirow{3}{*}{ FTD } \\
\hline $\mathrm{G} 2$ & 2o Ano & & & \\
\hline G3 & 3ㅇAno & & & \\
\hline $\mathrm{H} 1$ & 1읏 Ano & \multirow{3}{*}{$\begin{array}{l}\text { BIOLOGIA } \\
\text { MODERNA- } \\
\text { AMABIS \& } \\
\text { MARTHO }\end{array}$} & \multirow{3}{*}{$\begin{array}{c}\text { Gilberto Rodrigues Martho e } \\
\text { José Mariano Amabis }\end{array}$} & \multirow{3}{*}{ Moderna } \\
\hline $\mathrm{H} 2$ & 2Ano & & & \\
\hline $\mathrm{H} 3$ & 3o Ano & & & \\
\hline 11 & 10 Ano & \multirow{3}{*}{$\begin{array}{l}\text { CONEXÕES } \\
\text { COM A } \\
\text { BIOLOGIA }\end{array}$} & \multirow{3}{*}{$\begin{array}{c}\text { Eloci Peres Rios e Miguel } \\
\text { Thompson }\end{array}$} & \multirow{3}{*}{ Moderna } \\
\hline 12 & $2 \div$ Ano & & & \\
\hline 13 & 3o Ano & & & \\
\hline J1 & 10 Ano & \multirow{3}{*}{ BIOLOGIA } & \multirow{3}{*}{ Vivian Lavander Mendonça } & \multirow{3}{*}{ AJS } \\
\hline $\mathrm{J} 2$ & 2Ano & & & \\
\hline $\mathrm{J} 3$ & 3ㅇ Ano & & & \\
\hline
\end{tabular}

Fonte: Autoria própria (2018). 


\section{RESULTADOS E DISCUSSÃO}

Foram identificadas cento e quarenta e oito (148) imagens relacionadas aos trechos que abordavam o assunto HV, em diferentes volumes, nas dez (10) coleções investigadas. Entretanto, imagens sobre HV não foram identificadas em oito (8) volumes, dos trinta (30) analisados, sendo cinco (5) do primeiro ano, dois (2) do terceiro e um (1) do segundo ano do Ensino Médio (EM).

Do total de imagens, sessenta e oito (68) foram encontradas nos volumes do segundo ano do EM, representando uma frequência relativa de $46 \%$. Nos livros do terceiro ano, foram identificadas sessenta e duas (62) imagens, ou $42 \%$, enquanto nos livros de primeiro ano identificamos apenas dezoito (18) imagens, ou $12 \%$. De modo semelhante aos conteúdos textuais sobre HV, consideramos que o tradicional planejamento curricular dos conteúdos baseado na sequência dos níveis de organização dos seres vivos favorece essa frequência.

Em outras palavras, os conteúdos conceituais acerca da diversidade de microrganismos, plantas e animais geralmente são apresentados nos volumes do segundo ano, e os de EB (que também podem abordar a macroevolução dos seres vivos, aqui entendida como sinônimo de HV) tradicionalmente são encontrados nos livros do terceiro ano do Ensino Médio. Nesse sentido, espera-se uma maior frequência de imagens acompanhando possivelmente a maior frequência de fragmentos textuais que abordem a HV.

Nas subseções seguintes, discutiremos os resultados encontrados a partir de cada categoria de análise de imagens, como proposto na seção sobre os "Procedimentos Metodológicos" e presente na ficha de análise de imagens (Apêndice A).

\section{ANÁLISE EM FUNÇÃO DO GRAU DE ICONICIDADE}

Essa categoria de análise imagética leva em consideração sete (7) subcategorias. A distribuição de frequência destas subcategorias, organizadas por volume de coleção, é apresentada no Gráfico 1 a seguir. Esclarecemos que no quadro as subcategorias são enumeradas da seguinte maneira: 1 . Fotografia; 2. Desenho figurativo; 3. Desenho figurativo com signos; 4. Desenho figurativo com signos normalizados; 5. Desenho esquemático; 6 . Desenho esquemático com signos; e 7. Desenho esquemático com signos normalizados.

Dentre as sete (7) subcategorias, foram identificadas sessenta e duas (62) imagens classificadas como "Desenho figurativo", apresentando uma significativa frequência relativa de $42 \%$ do total de imagens (Gráfico 1 ). 
Gráfico 1 - Frequências de imagens classificadas quanto à tipologia (grau de iconicidade)

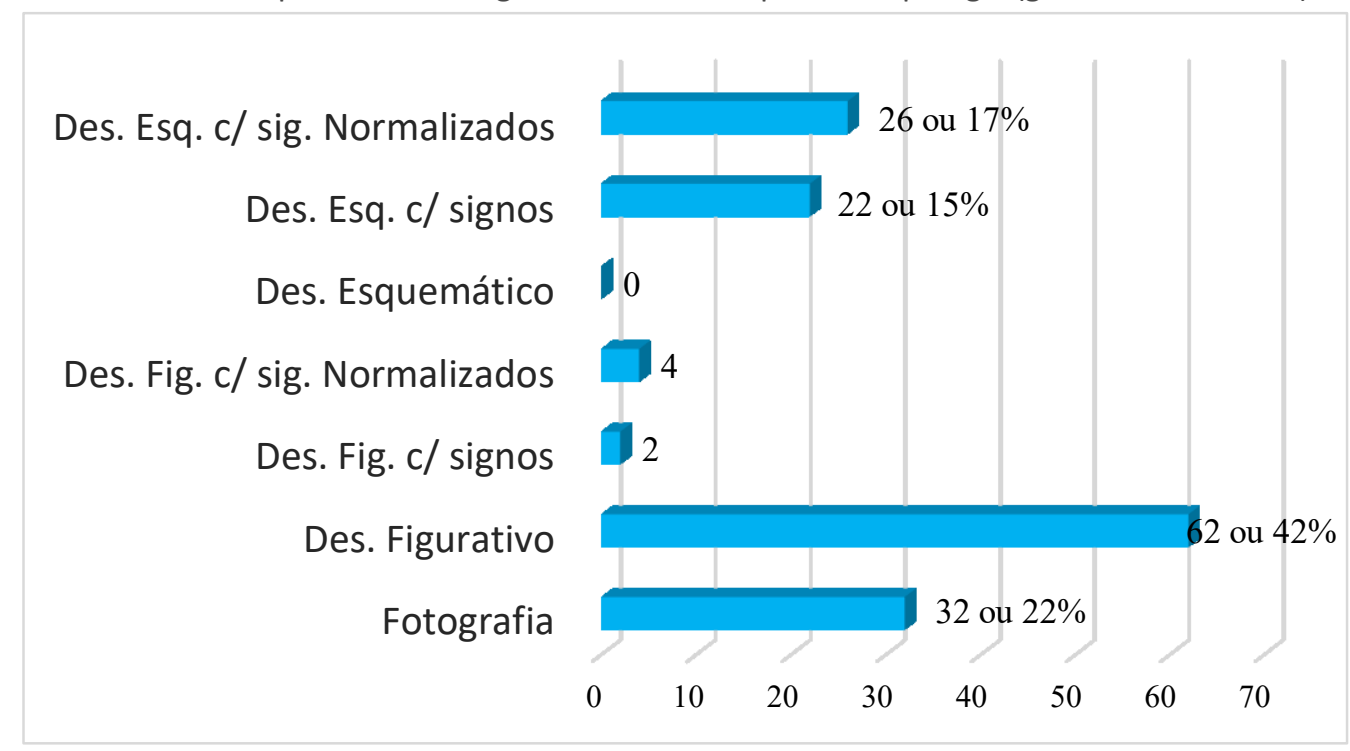

Fonte: Autoria própria (2018).

Consideramos essa frequência de desenhos figurativos um reflexo do tipo de conteúdo investigado. Tendo em vista que a HV aborda privilegiadamente a evolução dos grandes grupos de seres vivos, traçando caminhos evolutivos que ligam os seres vivos atuais a grupos ancestrais extintos, boa parte dessa história evolutiva é contada através de registros fósseis. Desse modo, geralmente esse assunto será ilustrado por representações artísticas, como por exemplo, de atmosferas primitivas como as florestas de grande porte do período Carbonífero e desenhos que procuram apresentar a possível aparência de uma espécie de grupos ancestrais já extintos, como dinossauros, como exemplificado na figura 1.

Figura 1 - Representação artística dos dinossauros

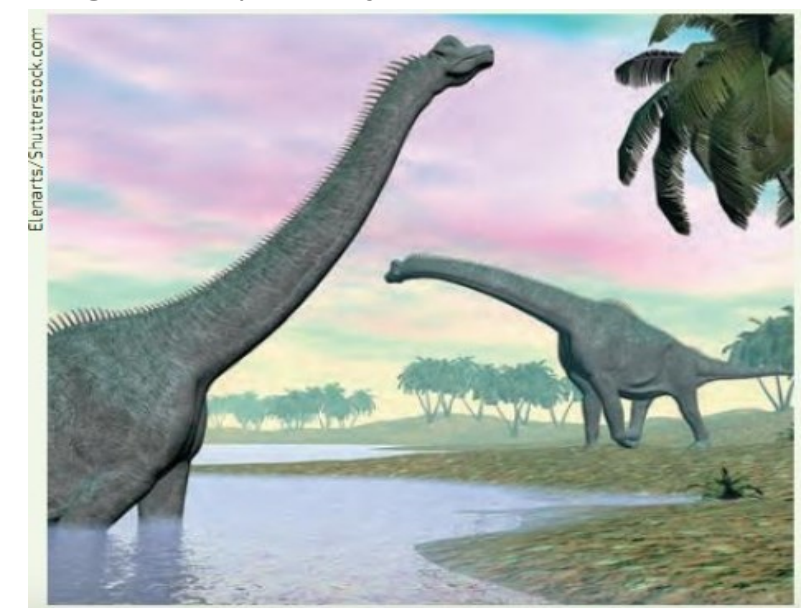

Fonte: Imagem retirada de F2, p. 205.

As Fotografias também apresentaram uma significativa frequência de $22 \%$ do total de imagens. Foram identificadas trinta e duas (32) imagens classificadas nessa subcategoria representada principalmente pelos mais variados tipos de fósseis, como ilustrado na figura 2. 
Figura 2 - Fóssil de trilobita que habitava os oceanos há cerca de 500 milhões de anos

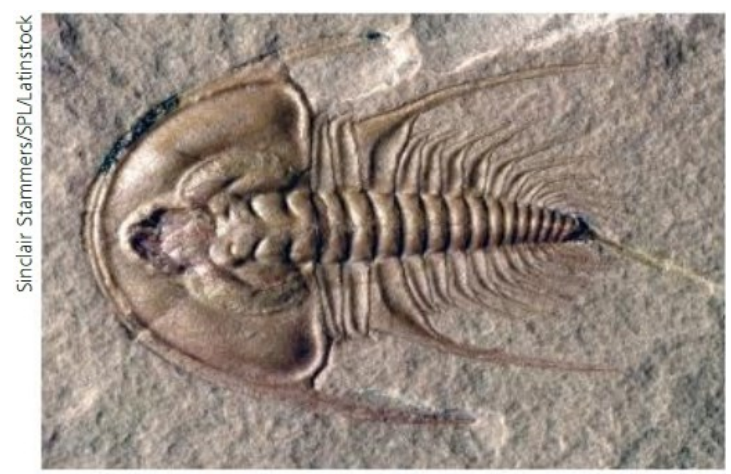

Fonte: Imagem retirada de G1, p. 23.

Além dessas, outras duas subcategorias se apresentaram relativamente frequentes, as ilustrações classificadas como "Desenho esquemático com signos normalizados" (26 imagens ou 17\%) e "Desenho esquemático com signos" (22 imagens ou 15\%). Nessas, as ilustrações valorizam a representação das relações bem como enfatizam ações ou magnitudes inobserváveis. Ao longo das coleções essas imagens ilustram questões evolutivas ligadas a filogenia, a relação de parentesco entre os seres vivos, como, por exemplo, as ilustrações que trazem cladogramas, como se pode verificar na figura 3.

Figura 3 - A relação de parentesco entre os seres vivos representada por uma árvore filogenética

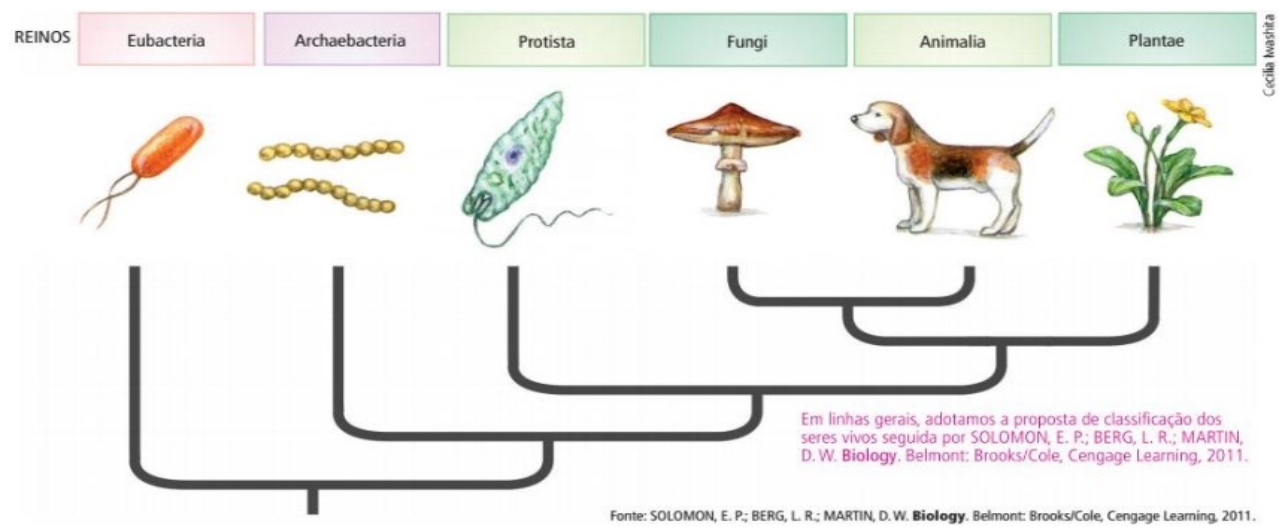

Fonte: Imagem retirada de G1, p. 24.

\section{ANÁLISE QUANTO À SUA FUNCIONALIDADE}

A análise funcional das imagens leva em consideração a finalidade da imagem no texto. Essa categoria é composta por três (3) subcategorias codificadas da seguinte maneira: 1 . Inoperante; 2 . Operativas elementares; e 3. Sintáticas.

Em relação as funções das imagens nos textos, a grande maioria foi classificada como "Inoperante", contabilizando oitenta e três (83) imagens ou 56\% do total. Dessa forma, tais imagens se apresentam sem nenhuma funcionalidade cabendo apenas a sua observação com caráter de entretenimento, ilustração ou exemplificação. Nesse aspecto, nossos resultados corroboram aqueles 
encontrados por Coutinho e colaboradores (2010) que, analisando LD de Biologia do Ensino Médio, identificaram uma grande frequência de imagens sem valor didático, o que pode ser considerado como um aspecto negativo do uso de imagens nos LD, uma vez que as ilustrações poderiam fornecer informações complementares, esclarecimentos acerca dos conceitos abordados no texto, ou mesmo, aproximações do conteúdo estudado com a realidade dos alunos. Nesse tipo de imagem, geralmente se apresentam ilustrações artísticas de algum organismo ou fóssil ancestral, como visualizado na Imagem 1 apresentada anteriormente.

A figura 1 apresenta uma representação artística de um dinossauro quadrúpede, herbívoro, podendo-se concluir que está baseada no estudo do registro fóssil. Embora a imagem claramente indique a que grupo de animais a ilustração evoca, para esta cabe apenas a observação. Entretanto, nessa figura poderiam ser trabalhadas, tanto no corpo do texto como na própria ilustração, questões que identificassem, por exemplo, de qual espécie se trata, em qual período tal organismo predominou e que influências esse animal ocasionou ao meio em que habitava. A ausência desses elementos limita o potencial uso didático que a imagem poderia apresentar no contexto do assunto.

A segunda subcategoria mais presente, dentre as imagens analisadas, são as classificadas como "Sintáticas" totalizando trinta e nove (39) imagens, representando cerca de $26 \%$ do todo. Nessas imagens encontramos elementos que exigem conhecimentos ou normas específicas, como ilustrado na figura 4, em que conhecimentos como leitura e interpretação de cladogramas, e o reconhecimento da evolução do grupo dos primatas a partir da perspectiva de árvores filogenéticas (ou da vida) são necessários.

Figura 4 - Diagrama das relações evolutivas entre os primatas

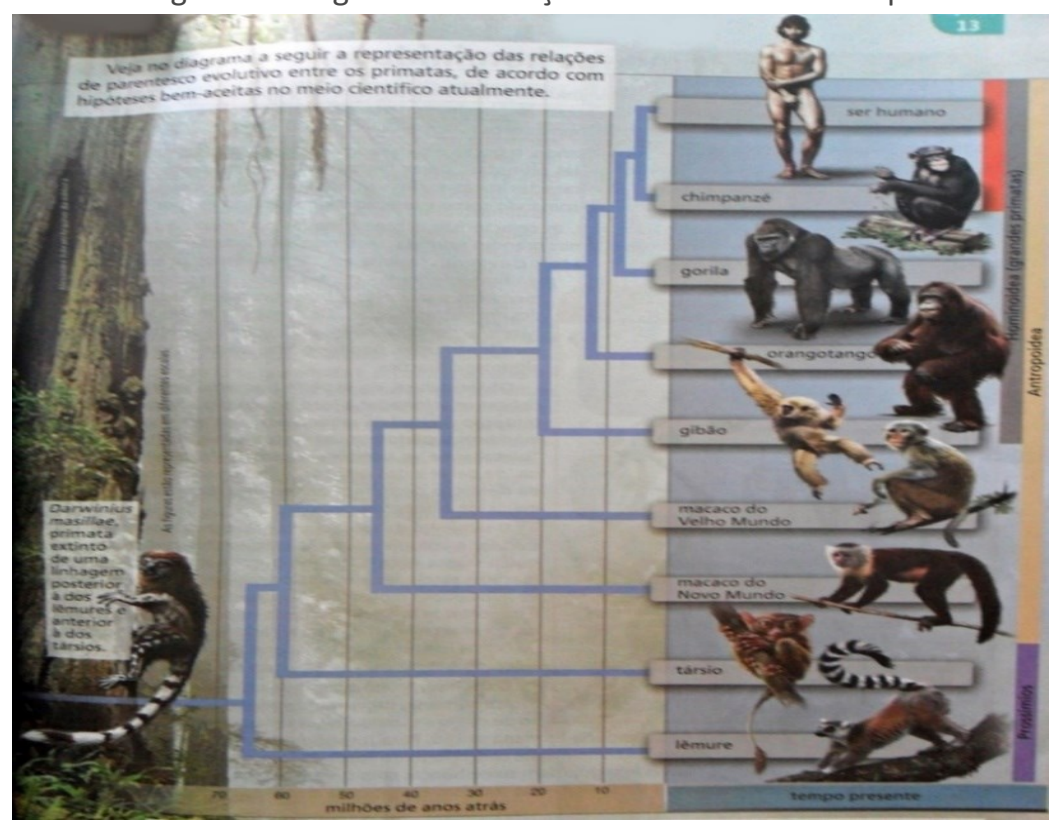

Fonte: Imagem retirada de J3, p. 267.

Além destas, foram identificadas vinte e seis (26) imagens classificadas na subcategoria "Operativas elementares", representando $18 \%$ do total. Nessa última 
subcategoria as imagens oferecem elementos que se apresentariam potencialmente de fácil entendimento, como é demonstrado na figura 5, a seguir.

Figura 5 - Esquema de um esqueleto de celacanto

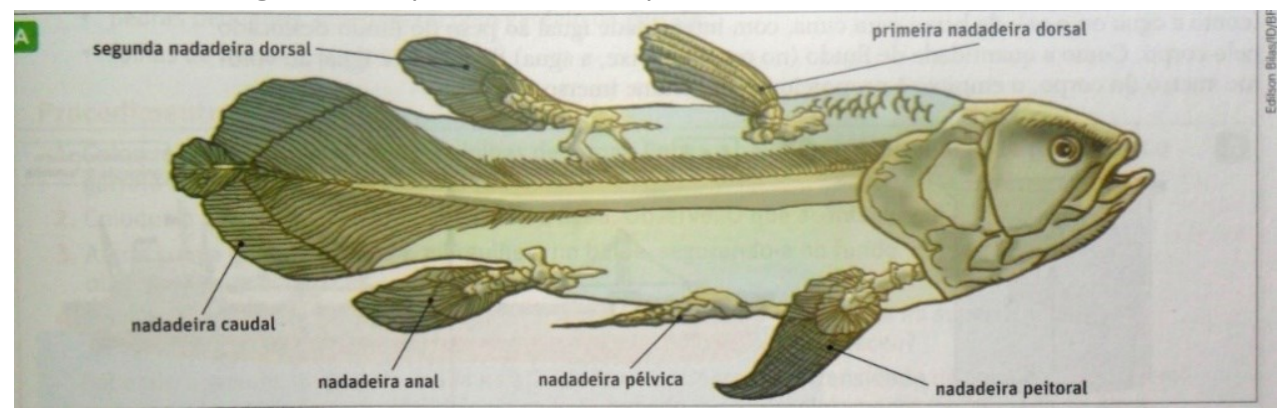

Fonte: Imagem retirada de C2, p. 191.

\section{ANÁLISE EM FUNÇÃO DA RELAÇÃO COM O TEXTO PRINCIPAL}

A análise imagética em função de sua relação com o texto principal, leva em consideração o entendimento que uma imagem pode aparecer isolada, em interação ou diretamente interligada ao texto. Desse modo, as imagens são codificadas da seguinte maneira: 1. Conotativa; 2. Denotativa; e 3. Sinóptica.

Em relação ao texto, oitenta e oito (88) imagens, representando 59\%, foram classificadas na subcategoria "Denotativa". Nesta subcategoria o texto descreve o conteúdo da imagem, fazendo sua menção, além de estabelecer uma relação de correspondência entre os elementos da ilustração e conteúdo textual. Ademais, nessas imagens os conteúdos inseridos são representados de forma explicita. Um exemplo que ilustra bem essa situação está disposto na figura 6 .

Figura 6 - Representação da transição do ambiente aquático para o ambiente terrestre

Alguns fósseis documentam a transição do ambiente aquático para o ambiente terrestre.

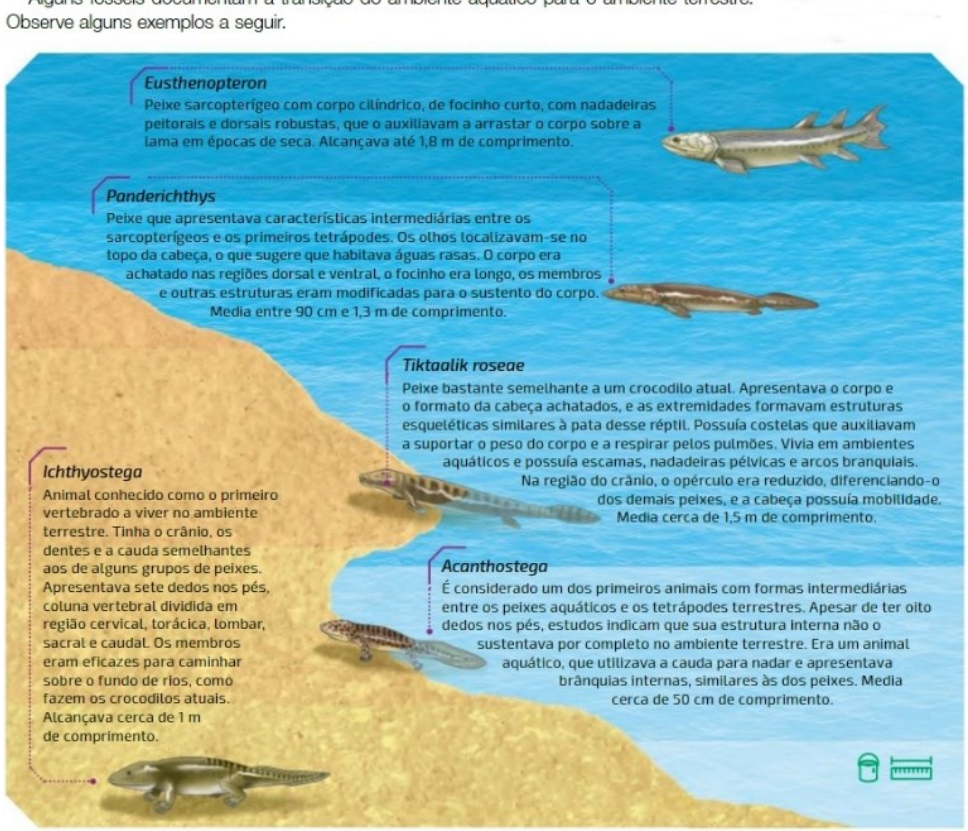

Fonte: Imagem retirada de F2, p. 195. 
Na figura 6, é possível verificar que o texto estabelece correspondência, tanto mencionando a presença da ilustração no trecho "Alguns fósseis documentam a transição do ambiente aquático para o ambiente terrestre. Observe alguns exemplos a seguir" (F2, p.195), como também, inserido na própria imagem, encontramos descrições que remetem aos elementos da ilustração e os conteúdos nela representados de forma explicita.

Jotta (2005) alerta para a importância de que o texto sempre remeta à imagem, para que se fomente uma articulação entre as linguagens verbal e visual, oferecendo elementos para uma melhor compreensão do texto e da decodificação da própria imagem. Tal aspecto é verificado com frequência ao longo de todas as coleções investigadas.

Dos resultados obtidos nesta subseção, o que se destaca é a quantidade de imagens classificadas com função "Conotativa" em relação ao texto principal: cinquenta e cinco (55) imagens ou $37 \%$ do total. Nesta subcategoria, o texto descreve os conteúdos sem mencionar sua correspondência com os elementos inclusos na ilustração, supondo que estas relações sejam óbvias e que o próprio leitor possa fazê-la. Embora em alguns casos isso ocorra com certa facilidade, existem outros momentos em que na mesma página se encontram mais de uma imagem, e que estas representam diferentes organismos que estão descritos no texto, no entanto, não se relacionando a descrição deste organismo na ilustração correspondente, o que acaba por confundir sua identificação pelo leitor, necessitando para isso, a intervenção direta do professor.

Quase metade das imagens identificadas como "conotativas" estavam em uma única coleção, a coleção I, totalizando vinte (20) imagens de cinquenta e cinco (55) possíveis. Esse dado pode implicar, por exemplo, que dependendo do tipo de finalidade que uma determinada imagem possa apresentar, a sua não menção no texto acaba por confundir ou até mesmo distanciar da real função que aquela ilustração possa apresentar ao conteúdo estudado. Um exemplo de imagem classificada como "conotativa", presente nesta coleção, é observado na figura 7.

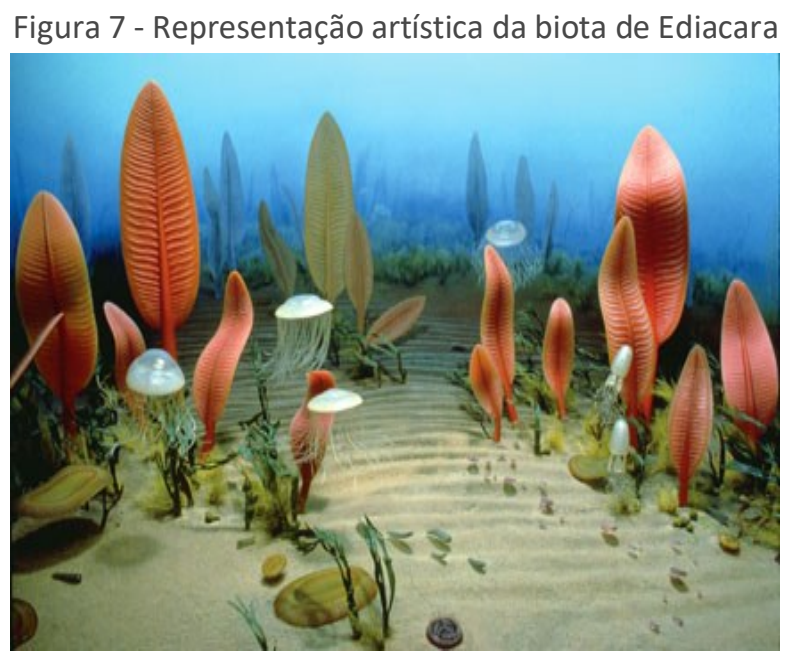

Fonte: Imagem retirada de I3, p. 22.

O texto que se relaciona indiretamente com a figura 7 descreve os registros fósseis de organismos eucariontes que surgiram há mais de 2 bilhões de anos e 
que há cerca de 1 bilhão de anos surgiram também os primeiros organismos pluricelulares, que correspondiam a algas filamentosas e alguns animais invertebrados. O texto enfatiza que tal evento evolutivo ficou conhecido como biota de Ediacara. No entanto, como o texto não relaciona essa descrição com os elementos contidos na imagem, acaba por distanciar, tanto no que se refere ao entendimento do que esta possa representar, como também sua potencialidade cognitiva.

A subcategoria "Sinóptica" foi a menos frequente dentre as três (3) subcategorias analisadas aqui, somando apenas cinco (5) imagens ou $4 \%$ do total. Nesta subcategoria a ilustração e os conteúdos textuais se relacionam de modo indivisível. O texto e imagem se apresentam como uma unidade, e que ocorrendo a separação entre esses elementos o sentido como um todo acaba sendo perdido. Um exemplo de ilustração classificada como "sinóptica" é apresentado na figura 8.

Figura 8 - Evolução dos vertebrados

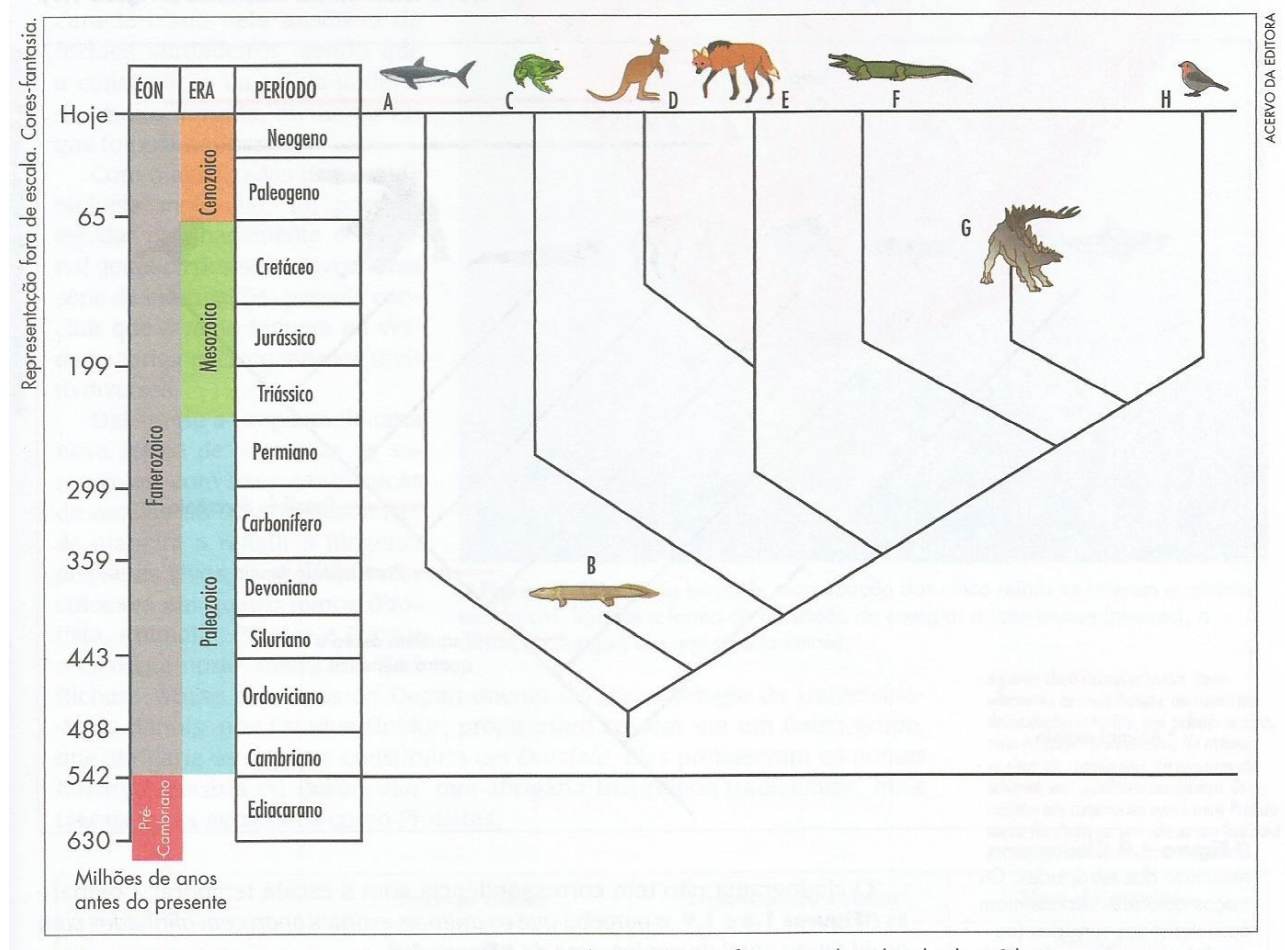

Fonte: Imagem retirada de B2, p. 15.

O texto que remete a figura 8 descreve e chama a atenção para algumas relações de parentesco evolutivo entre alguns grupos particulares, de forma que, quando observamos apenas a ilustração, sem com isso relacioná-la ao texto, temos apenas uma imagem apresentando algumas relações filogenéticas entre alguns grupos ao longo de milhares de anos. Contudo, no texto é enfatizado que ancestrais do canguru (indicado com a letra "D" na imagem), por exemplo, começou a divergir dos demais mamíferos no jurássico, e que a divergência básica entre a linhagem dos mamíferos e a que deu origem aos dinossauros (indicado com a letra "G") ocorreu ainda na era Paleozoica. Com isso, além do caráter denotativo, texto e imagem estabelecem condições nas quais os elementos inclusos na ilustração são demarcados e enfatizados, formando assim uma unidade indivisível. 


\section{ANÁLISE EM FUNÇÃO DAS ETIQUETAS VERBAIS}

Com relação a forma de apresentação das imagens, as etiquetas verbais apresentam-se bastante diferenciadas nos LD analisados. Nessa categoria, as imagens puderam ser classificadas em: 1 . Sem etiqueta; 2 . Nominativa; e 3. Relacionável.

Do total de imagens analisadas (148), sessenta e cinco (65) imagens se encontram sem etiquetas verbais, com etiquetas verbais nominativas cinquenta $\mathrm{e}$ oito (58) e relacionáveis vinte e cinco (25), apresentando índices de frequência em torno de $44 \%, 39 \%$ e $17 \%$ respectivamente. Esses dados indicam a necessidade de se aperfeiçoar tais ilustrações, para que estas, possam assim, auxiliar os alunos na compreensão das representações visuais, já que a subcategoria "Sem etiqueta" se apresentou como a mais frequente.

As coleções didáticas que apresentaram maior quantidade de imagens sem etiquetas, ou alguma legenda explicativa, são as coleções $A, C$ e $E$, com um percentual de 14\% (9 em 65) cada uma. Por sua vez, a legenda "Nominativa" se encontra com maior frequência nas coleções B, com percentuais de $28 \%$ (16 em 58), C e I ambos com, 19\% (11 em 58) cada. Já nas coleções B e C as imagens com legendas "Relacionáveis" prevaleceram ambas com 28\% (7 em 25) cada. Nesta subcategoria as imagens apresentam grande quantidade de etiquetas explicativas que proporcionam aos alunos melhores condições de entendimento.

Em nenhuma das cento e quarenta e oito (148) imagens investigadas se observou problemas de falta de nitidez e as ilustrações, em sua maioria, com exceção das tabelas, apresentaram-se coloridas. Em todos os desenhos e esquemas as ilustrações possuem cores fortes e destacadas, tais como amarelo, azul, laranja, verde, vermelho, roxo e rosa, bastante contrastadas e apresentando uma diversidade de detalhes. Em todas as coleções se faz referência, seja na legenda ou no rodapé da página, que as cores utilizadas são "fantasia", evidenciando que estas não correspondem às colorações próximas ou reais do exemplo ilustrado.

\section{CONSIDERAÇÕES FINAIS}

Com a presente investigação, buscamos verificar o papel didático das imagens relacionadas à HV presentes nos LD de Biologia do Ensino Médio aprovados na edição de 2018 do Programa Nacional do Livro Didático (PNLD-2018). Os dados imagéticos foram analisados tendo como base a ficha analítica modificada de Ferreira (2014) e Ferreira e Oliveira (2016), apresentada no Apêndice A desse texto.

Analisamos todas as dez (10) coleções de livros didáticos (LD) aprovadas no PNLD-2018. Cada coleção estava organizada em três (3) volumes, resultando no total de trinta (30) livros investigados. Entretanto, destaca-se que as cento e quarenta e oito (148) imagens que compuseram nosso corpus de análise imagética estavam presentes em 22 volumes (livros), não tendo sido identificados imagens sobre HV em cinco (5) livros do primeiro ano, dois (2) livros do terceiro e em um (1) livro do segundo ano do EM. 
A análise imagética realizada corrobora com algumas investigações já realizadas que tiveram como foco a análise de imagens em materiais didáticos de Biologia, como Barros e Carneiro (2005), Coutinho et al. (2010), Ferreira (2014), Gibin, Kill e Ferreira (2009) e Jotta (2005). Enfatizamos que este estudo não procurou classificar quais as melhores e piores coleções didáticas, dentre as analisadas, mas sim, sinalizar alguns papeis didáticos desempenhados pelas imagens e suas possíveis contribuições no processo de ensino-aprendizagem de Biologia no EM.

Os resultados obtidos na análise das imagens apontam que $56 \%$ foi classificada como "Inoperante", não apresentando nenhuma funcionalidade didática no LD, apenas um caráter estético, para observação. Nesse aspecto, pesa o fato de que as imagens têm sido cada vez mais utilizadas nos LD a fim de melhorar a compreensão dos conteúdos de Biologia. Apesar de seu valor atrativo, espera-se que estas imagens não fiquem restritas somente a este papel, em outras palavras, de função estética e possivelmente inoperante. Autores da área apontam que as imagens presentes nos LD precisam realmente se relacionar com o texto, objetivando sua complementação e fundamentação. Dessas imagens espera-se, enquanto ilustrações técnicas, que tenham funções significativamente cognitivas e que assim possam agregar valor aos textos e explicações científicas, como aponta Santaella (2002), alcançando funcionalidades que extrapolem sua inserção como meros elementos de configuração gráfica da obra.

Com a presente pesquisa, esperamos contribuir para a ampliação do conhecimento sobre os LD de Biologia do EM. Assim, para que as imagens, tanto quanto os conteúdos textuais, consigam atender às expectativas demandadas pela sua utilização no processo de ensino-aprendizagem, novas investigações nesse âmbito precisam ser realizadas. Além disso, procuramos (re)avaliar as imagens presentes e sugerir que esse, e demais estudos semelhantes, possam ser levados em consideração pelos professores em formação e em exercício, quando da escolha e/ou utilização dos LD em sala de aula, ou mesmo na elaboração de novos LD, com a finalidade de atualizá-los e tornar o seu uso realmente efetivo.

Dessa maneira, é esperado que os LD distribuídos nas escolas públicas possuam conteúdos atualizados e livres de equívocos, tendo em vista que, geralmente, ocupam um papel central como recurso utilizado para o trabalho do professor em sala de aula. Contudo, é necessário se enfatizar, que em parte, desde o início da implementação das políticas públicas de avaliação dos livros didáticos no PNLD, este tem contribuído no sentido de diminuir tais equívocos nos últimos anos. 


\title{
History of life images' analysis in high school biology textbooks
}

\begin{abstract}
The Biological Sciences Degree Course should enable undergraduates to understand how life has been organized over time, implying an understanding of evolutionary mechanisms as an integrating axis of initial teacher training. Therefore, history has shown that since man began to ask himself about the origin of the first living beings, ideas of a mythological, philosophical, religious, and scientific nature were outlined and gained enormous space in discussions about the History of Life ( $\mathrm{HL})$. These discussions are present in high school biology classes, often reverberating in mixed explanations that hinder the appropriation of biological knowledge. In our investigation, we considered the HL as a topic of Biological Evolution teaching since it concerns the macroevolutionary processes responsible for the emergence of large groups of living beings. As already mentioned, the objective of this research is to verify the didactic role of the images related to HV which are present in the High School Biology Textbooks approved in the 2018 edition of the National Textbook Program (PNLD-2018). From this perspective, we opted for the use of an analytical instrument, built from semiotic analysis references, to understand the illustrated aspects of the subject HV in the investigated material. Thus, we found that the majority of analyzed images can be classified as inoperative, which means that there is no functionality beyond illustration. From this result, the fact is that images have been increasingly used in textbooks in order to improve the understanding of the conceptual contents of Biology. Hence, in order for the imagery contents to be able to the expected demands by them in the teachinglearning process, further investigations in this area need to be carried out.
\end{abstract}

KEYWORDS: Biological Evolution. Macroevolution. Imagetic Analysis. PNLD-2018. 


\section{AGRADECIMENTOS}

Os autores agradecem à Coordenação de Aperfeiçoamento de Pessoal de Nível Superior (CAPES) por conceder a bolsa de iniciação à docência do primeiro autor (PIBID) e à Fundação de Amparo à Pesquisa do Estado da Bahia (FAPESB) por conceder a bolsa de doutorado do segundo autor, o que auxiliou na investigação realizada e divulgada nesse texto.

\section{REFERÊNCIAS}

ARAÚJO, M. F. F. de.; MENEZES A.; COSTA, I. A. S. da. História da Biologia. 2. ed. Natal: EDUFRN, 2012.

BARROS, M. M. V.; CARNEIRO, M. H. S. Os conhecimentos que os alunos utilizam para ler as imagens de mitose e de meiose e as dificuldades apresentadas. In: Encontro Nacional de Pesquisa em Ensino de Ciências, V. Atas do V ENPEC, ABRAPEC: 2005. Disponível em:

http://www.nutes.ufrj.br/abrapec/venpec/conteudo/artigos/3/pdf/p319.pdf. Acesso em: 07 ago. 2018.

BIZZO, N.; EL-HANI, C. O arranjo curricular do ensino de evolução e as relações entre os trabalhos de Charles Darwin e Gregor Mendel. Filosofia e História da Biologia, v. 4, n. 1, p. 235-257, 2009.

BRASIL. Base Nacional Comum Curricular (BNCC). Brasília: Ministério da Educação, 2017. Disponível em:

http://basenacionalcomum.mec.gov.br/wpcontent/uploads/2018/04/BNCC_Ensi noMedio_embaixa_site.pdf. Acesso em: 15 jul. 2018.

BRASIL. Guia de livros didáticos: PNLD 2018: Biologia. Brasília, Ministério da Educação/Secretaria de Educação Básica, 2017.

BENTON, M. J. História da vida. Porto Alegre: Editora L\&PM, 2012.

COUTINHO, F. et al. Análise do valor didático de imagens presentes em livros didáticos de Biologia para o ensino médio. Revista Brasileira de Pesquisa em Educação em Ciências (RBPEC), São Paulo, vol. 10, no. 3, não paginado, 2010. Disponível em: https://seer.ufmg.br/index.php/rbpec/article/view/2287/1686. Acesso em: 15 ago. 2018.

COSTA, V. S. Trazendo a macroevolução para a sala de aula: Ensinando biologia evolutiva de forma pluralista e integrada. 2017. 222 f. Dissertação (Mestrado) Curso de Licenciatura em Ciências Biológicas, Programa de Pós-graduação em Ensino, Filosofia e História das Ciências, Universidade Federal da Bahia, Salvador, 2017. Disponível em:

https://repositorio.ufba.br/ri/bitstream/ri/23385/1/Dissertação Final Vanderson Costa.pdf. Acesso em: 25 mai. 2018. 
DIAS, B. C. Macroevolução. 2008. Disponível em: http://polegaropositor.com.br/biologia/macroevolucao/. Acesso em: 11 jul. 2018b.

FERREIRA, R. A. Análise de imagens referentes ao ensino de anatomia e fisiologia humanas em apostilas didáticas de biologia. 2014. $44 \mathrm{f}$. Monografia (Especialização) - Ensino de Ciências e Matemática, Universidade Estadual de Santa Cruz, Ilhéus, 2014.

FERREIRA, R. A.; OLIVEIRA, M. C. A. Instrumental para análise de imagens em materiais didáticos de Ciências e Biologia. Revista da SBEnBio, v.9, p. 3963-3971, 2016.

GIBIN, G. B.; KIILL, K. B.; FERREIRA, L. H. Categorização das imagens referentes ao tema equilíbrio químico nos livros aprovados pelo PNLEM. Revista Electrónica de Enseñanza de las Ciencias, v. 8. no 2. 2009. Disponível em: http://reec.uvigo.es/volumenes/volumen8/ART18_Vol8_N2.pdf. Acesso em: 05 ago. 2018.

GIL, A. C. Como elaborar projetos de pesquisa. São Paulo: Atlas, 2002.

JOTTA, L. A. C. V. Embriologia animal: uma análise dos livros didáticos de biologia do ensino médio. 2005. 245 f. Dissertação (Mestrado em Educação) -

Universidade de Brasília, Brasília, 2005. Disponível em: http://repositorio.unb.br/bitstream/10482/5011/1/2005_LeiladeAragaoCVJotta. pdf. Acesso em: 18 ago. 2018.

LAJOLO, M. Livro Didático: um (quase) manual de usuário. Em Aberto, Brasília, ano 16, n. 69, jan./mar. 1996. Disponível em:

http://emaberto.inep.gov.br/index.php/emaberto/issue/view/231. Acesso em: 15 mar. 2018.

LICATTI, F. O ensino de evolução biológica no nível médio: investigando concepções de professores de biologia. 2005. 240 f. Dissertação (Mestrado em Ensino de Ciências.) - Faculdade de Ciências, Universidade Estadual Paulista, São Paulo, 2005.

NICOLINI, L. B.; FALCÃO, E. B. M.; FARIA, F. S. Origem da vida: como licenciandos em Ciências Biológicas lidam com este tema? Ciência \& Educação, Bauru-SP, vol. 16, no 02, p. 355-367, abr. 2010.

NUÑES, I. B. et al. O livro didático para o ensino de ciências. Seleciona-los: um desafio para os professores do ensino fundamental. In III Encontro Nacional de Pesquisa em Educação em Ciências (III ENPEC), 2001. Atas do V ENPEC, ABRAPEC: 2001. Disponível em:

http://www.nutes.ufrj.br/abrapec/iiienpec/Atas\%20em\%20html/o85.htm. Acesso em: 13 nov. 2018.

OLIVEIRA, M. C. A. de. A origem dos seres vivos na biologia do ensino médio: construindo conhecimentos a partir da dinâmica do júri simulado. In: V Encontro Regional Sul de Ensino de Biologia (EREBIO-Sul) e IV Simpósio Latino Americano e 
Caribenho de Educação em Ciências do International Council of Associations for Science Education (ICASE). Londrina-PR. Atas [...], Londrina, 2011.

OLIVEIRA, G. S. Aceitação/rejeição da Evolução Biológica: atitudes de alunos da Educação Básica. Dissertação (Mestrado) - Faculdade de Educação, Universidade de São Paulo, São Paulo, 2009.

ROSA, M. D.; ARTUSO, A. R. O uso do livro didático de Ciências de 6a a 9a ano: um estudo com professores brasileiros. Revista Brasileira de Pesquisa em Educação em Ciências (RBPEC), São Paulo, v. 19, p. 709-746, 2019.

SALGADO-LABOURIAU, M. L. História ecológica da terra. 2. ed. São Paulo: Edgard Blücher Ltda, 2014. 307 p.

SANTAELLA, L. O que é semiótica. São Paulo: Brasiliense. Coleção primeiros passos. 2002.

\section{APÊNDICE A}

Ficha de análise das imagens presentes nas coleções de LD de Biologia aprovados no PNLD - 2018, com base nas categorizações adaptadas de Ferreira (2014).

\begin{tabular}{|c|c|c|c|c|c|}
\hline \multicolumn{6}{|c|}{ Identificação do livro didático: } \\
\hline \multicolumn{6}{|c|}{ Grupo 1: Análise em função do Grau de Iconicidade } \\
\hline Categoria & Incidência & Categoria & Incidência & Categoria & Incidência \\
\hline Fotografia & & $\begin{array}{c}\text { Desenho } \\
\text { figurativo } \\
\text { com signos } \\
\text { normalizados }\end{array}$ & & $\begin{array}{c}\text { Desenho } \\
\text { esquemático } \\
\text { com signos } \\
\text { normalizados }\end{array}$ & \\
\hline $\begin{array}{l}\text { Desenho } \\
\text { figurativo }\end{array}$ & & $\begin{array}{c}\text { Desenho } \\
\text { esquemático }\end{array}$ & & $\begin{array}{c}\text { Subcategorias } \\
\text { combinadas }\end{array}$ & \\
\hline $\begin{array}{c}\text { Desenho } \\
\text { figurativo com } \\
\text { signos } \\
\end{array}$ & & $\begin{array}{c}\text { Desenho } \\
\text { esquemático } \\
\text { com signos }\end{array}$ & & & \\
\hline \multicolumn{6}{|c|}{ Grupo 2: Análise em função da Funcionalidade } \\
\hline Categoria & Incidência & Categoria & Incidência & Categoria & Incidência \\
\hline Inoperantes & & $\begin{array}{c}\text { Operativas } \\
\text { elementares }\end{array}$ & & Sintáticas & \\
\hline \multicolumn{6}{|c|}{ Grupo 3: Análise em função da relação com o texto principal } \\
\hline Categoria & Incidência & Categoria & Incidência & Categoria & Incidência \\
\hline Conotativa & & Denotativa & & Sinóptica & \\
\hline \multicolumn{6}{|c|}{ Grupo 4: Análise em função das Etiquetas Verbais } \\
\hline Categoria & Incidência & Categoria & Incidência & Categoria & Incidência \\
\hline Sem etiqueta & & Nominativa & & Relacionável & \\
\hline
\end{tabular}


Recebido: 26 mar. 2020

Aprovado: 12 jun. 2020

DOI: 10.3895/actio.v5n2.11843

Como citar:

LIMA, S. A. D. de.; OLIVEIRA, M. C. A. de.; ROSA, M. D. Análises das imagens de história da vida em livros didáticos de biologia do ensino médio. ACTIO, Curitiba, v. 5, n. 2, p. 1-24, mai./ago. 2020. Disponível em: $<$ https://periodicos.utfpr.edu.br/actio>. Acesso em: XXX

Correspondência:

Steve Allen Davi de Limal

Av. da Universidade, s/n - Coqueiros - Itapipoca, Ceará, Brasil.

Direito autoral: Este artigo está licenciado sob os termos da Licença Creative Commons-Atribuição 4.0

Internacional.

(c) (1) 